\title{
Mental distress among frontline healthcare workers outside the central epidemic area during the novel coronavirus disease (COVID-19) outbreak in China:A cross-sectional study
}

\section{YaYun Liu}

department of infectious diseases,Shanghai changhai hospital https://orcid.org/0000-0002-4530-

1873

XinSheng Liu

Department of Medical Administration,Jinzhong Health Committee of Shanxi province

Bai Gao

department pf information,shanghai changhai hospital

chengzhong Li

department of infectious diseases,Shanghai changhai hospital

xuesong Liang ( $\sim$ liangxuesong2000@163.com )

https://orcid.org/0000-0003-0527-4978

\section{Research}

Keywords: perceived stress, anxiety, depression, frontline healthcare worker, 2019 coronavirus disease(COVID-19)

Posted Date: June 9th, 2020

DOI: https://doi.org/10.21203/rs.3.rs-32833/v1

License: (c) (i) This work is licensed under a Creative Commons Attribution 4.0 International License. Read Full License 


\section{Abstract}

Background and aim:At the initial stage of the fight against COVID-19, a large number of medical staff and materials were dispatched to Wuhan City and Hubei Province to contain the outbreak quickly and effectively. The national infection prevention and control strategy posed a challenge to the physical and psychological resilience of frontline healthcare workers(HCWs) outside the central epidemic area.This study aims to survey frontline HCWs outside the central epidemic area in China to understand their levels of perceived stress, anxiety, and depression during the initial stage of the fight against the COVID-19 outbreak.

Methods: From February 11 to February14, 2020, an online survey was conducted in Jinzhong, Shanxi Province using snowball sampling techniques. The survey consisted of two parts, namely, demographic data and psychological screening. Demographic information included gender, age, hospital classification, working department, profession type, and working experience. Perceived stress was assessed by Chinese simple Perceived Stress Scale 10, general anxiety was assessed by the General Anxiety Disorder Scale, and depression was evaluated by the Patient Health Questionnaire-9.

Results: A total of 1,315 HCWs were included, of which 646(49.1\%) reported a moderate to severe stress (scores $\geq 14$ ), $141(10.7 \%$ ) reported moderate to severe anxiety (score $\geq 10$ ), and $164(12.4 \%)$ reported a major depression (score $\geq 10$ ). Female gender was significantly associated with high levels of perceived stress, anxiety, and depression $(P<0.05)$, and working time was negatively correlated with the level of perceived stress, anxiety, and depression $(P<0.05)$. Statistical difference was observed in perceived stress score among different age groups, levels of hospital group, and working departments $(P<0.05)$.

Conclusion: During the initial stage of the fight against COVID-19 in China, more than half of the frontline HCWs outside the central epidemic area rated perceived stress as moderate to severe, and nearly $23 \%$ of them reported moderate to severe anxiety or depression. Female gender, low hospital level, and emergency department were associated with a high level of perceived stress.

\section{Introduction}

Since late December 2019,many atypical pneumonia cases were reported in Wuhan, Hubei Province, China[1].Over57,000 confirmed cases of the novel coronavirus disease(COVID-19) in nearly 200countries were reported in March 31,2020, and COVID-19 has caused a large global outbreak and is now a major public health issue[2]. The COVID-19 infection outbreak is an emerging, rapidly evolving situation. The major rout of transmission of the COVID-19 is droplet and close contact[3]. In the healthcare setting, certain treatments and procedures contributed to increased transmission. Healthcare workers $(\mathrm{HCWs})$ are the highest risk group for infection by the COVID-19virus [4].In February 24, 2020, the National Health Commission of the People's Republic of China reported in the press conference of WHO-China Joint Mission on COVID-19that 3,387 HCWs have been confirmed infected with COVID-19, with 22 (0.6\%) deaths[5]. 
Given the increasing number of patients and suspected cases, the COVID-19 outbreak has caused public panic and mental health stress.Moreover, the increasing scope of outbreak-affected countries has generated public anxiety. The HCWs who are working under extreme stress and who are caring for infected individuals have felt scared or experienced significant psychological conflict between their duties and their concern for their own safety during the COVID-19 outbreak[6-9].Therefore, during the outbreak, China has been handling public psychological barriers and performing psychological crisis intervention when the public health emergency responses initiated. Surveys were conducted to determine the risk factors and the mental stress status of the general public, and members and nonmembers of medical teams aided in COVID-19 control [10-12].However, during the fight of COVID-19 in China, nearly 30,000 medical workers were dispatched to Wuhan City and Hubei Province to address the shortage of medical workers and protective materials in the central epidemic. However, HCWs outside Wuhan City and Hubei Province may need to bear more pressure due to shortage of personal protective equipment, colleagues, and experts. Therefore, the primary objective of this study is to determine the perceived stress and clinically significant symptoms of depression and anxiety in a large representative sample of frontline HCWs fighting COVID-19 outside Wuhan City and Hubei Province. We used three screening scales that were widely used in general psychiatric practical, namely, the Chinese simple Perceived Stress Scale 10 (C-PSS-10), the General Anxiety Disorder Scale (GAD-7) for anxiety, and the Patient Health Questionnaire9(PHQ9)for depression. Our secondary goal was to identify the risk factors associated with the psychological status to determine whether intervention should be offered selectively,particularly targeted toward high-risk individuals.

\section{Methods}

\section{Settings and participants}

The study was a descriptive one. It aimed to evaluate the psychological stress caused by the COVID-19 outbreak on HCWs outside the central epidemic area. To reduce the transmission possibility of face-toface contact and communication and avoidance of large gatherings and activities, we initiated a survey using a mobile app questionnaire from February 11 to February14, 2020. Frontline medical staff included various persons who provided medical services to suspected or confirmed COVID-19 personnel during the fight against the COVID-19 epidemic. They included nurses, physicians, and laboratory and radiology workers. The Ethics Committee of Shanghai Changhai Hospital approved the study. All participants were asked to sign a written informed consent before beginning the survey.

\section{Survey development}

Demographic data included gender, age, education, hospital classification, and years of working, departments, and professional type. The psychometric questionnaire included two parts, namely, perceived stress screening and mental illness screening (anxiety and depression). A classic stress assessment instrument, the Chinese version of the PSS (C-PSS-10)[13],was used for perceived stress screening, whereas GAD-7[14] and PHQ9[15]were used to assess anxiety and depression. 


\section{Definitions and scores}

The validity and reliability of the C-PSS-10, GAD-7, and PHQ-9 test have been confirmed previously in different studies worldwide [16-18].

The C-PSS-10comprises 10 items, 6 negative questions (1,2,3,6,9,and10) and 4 positive questions $(4,5,7$, and 8), in which the participants were asked to base their answers on their feelings on the last month to respond to each question fairly quickly. The item score ranged from 0 (never) to 4 (very often), resulting in a sum score range from 0 to 40 .Individuals with high scores indicated high perceiver stress. Scores ranging from 0 to 13 were considered low stress,14-26 were considered moderate stress, and 27-40 were considered severe perceived stress.

The GAD-7 is a screening tool and severity measure for generalized anxiety disorder. The participants should mark the response that best applies to them over the last 14 days. The item score ranged from 0 (not at all) to 3(nearly every day), resulting in a sum score range from 0 to 21 . Scores of 5,10 , and 15 were considered the cut-off points for mild, moderate, and severe anxiety, respectively.

PHQ-9 is a self-administered version of the PRIME-MD diagnostic instrument for common mental disorders. It is used to make a tentative diagnosis of depression in at-risk populations. The participants were asked to mark the response that best applies to them over the last 7days, and the score ranged from 0 (not at all) to 3 (nearly every day). PHQ-9 scale contained 9 items, of which 1, 4,and 9 were the core items. Any one of the core items with a score of $>1$ needs attention because items 1 and 4 represent the core symptoms of depression, and item 9 indicates self-injury. A PHQ-9 score of $\geq 10$ had a sensitivity of $88 \%$ and specificity of $88 \%$ for major depression.

\section{Statistical methods}

The abnormal distribute continuous data were described as median and interquartile(IQR). KruskalWallis univariate analysis was used to test the difference of the stress, anxiety,and depression score among different groups. Categorical variables were also compared using Kruskal-Wallis univariate analysis. Correlation between demographic variates and mental impact degree was analyzed using Spearman test. All tests were two-tailed, and $P<0.05$ indicated statistically significant. Analyses were performed using SPSS version 21.0(IBM SPSS, New York,USA).

\section{Results}

\section{Survey respondents}

In this study, we used snowball sampling strategy to implement the online survey. We focused on recruiting frontline HCWs fighting against the COVID-19 outbreak outside the central epidemic area(i.e., Wuhan City and Hubei Province). The survey was initially disseminated to the Department of Medical Administration, Jinzhong Health Committee of Shanxi Province and was then passed to hospitals at all 
levels. These hospitals were designated to fight against the COVID-19 outbreak and were center for disease control and prevention.

Overall,we received 1,317 completed questionnaires, of which 2 were rejected due to age errors, and final 1,315 respondents were valid. The validity rate was $99.85 \%$.

\section{Demographic characteristics of respondents}

As shown in Table1, the majority of the frontline HCWs were women, with median age of 37 years. Nearly half of the female HCWs were well educated (bachelor degree: $49.9 \%)$. Moreover, $97.6 \%(1,284 / 1,315)$ of the frontline HCWs worked in hospitals, and more than half of them worked in public hospitals $(60.2 \%)$.Less than $20 \%$ of these HCWs worked in isolation wards, and most of them had been participating in the fight against the COVID-19 outbreak in fever clinics, emergency departments, and other auxiliary examination departments.In the battle against the COVID-19 outbreak, physicians and nurses accounted for more than $80 \%$, and most of them were experienced HCWs with work time of more than $10 y e a r s$.

\section{Psychological effect of COVID-19 outbreak}

The psychological effect of the COVID-19 outbreak on frontline HCWs was evaluated in two aspects. The first aspect was perceived stress. The median PSS score of the frontline HCWs was $13($ IQR, 9, 18), and $646(49.1 \%)$ of these HCWs reported a moderate to severe stress (score $\geq 14)$. Then, general anxiety and depression were evaluated using GAD-7 and PHQ-9, respectively. Of the respondents, 806(61.3\%) were considered to have a normal score (score: $0-4), 368(28 \%)$ were considered to suffer from mild anxiety (score:5-9), 74 (5.6\%) were considered to suffer from moderate anxiety (score: 10-14), and 67(5.09\%) were considered to suffer from severe anxiety (score: $\geq 15$ ). For depression screening, $164(12.4 \%)$ reported a major depression (score: $\geq 10) ; 221(16.8 \%)$ reported at least one core item (score:>1), of which 123(9.4\%) with either item 1or 4 (score:>1) and 22(1.7\%) with item 9 (score:>1).Collectively, we found that during the early stage of the fight against COVID-19, most frontline HCWs outside the central epidemic area had moderate to severe perceived stress, and nearly a quarter had moderate to severe anxiety or depressive performance that deserves attention.

\section{Demographic variables and perceived stress}

As shown in Table 2, female HCWs had significant higher median PSS than male coworkers (14 vs. 12, $P<0.001)$, and female gender was positively correlated with perceived stress degree $(r=0.097, P<0.001)$. Both the median PSS and the perceived stress degree of different age groups differed significantly and the age was negatively correlated with the PSS. Further pairwise comparison found that the PSS of $\leq 30-$ year-old group and 30 to 40 -year-old group were significantly higher than that of 40 to 50 -year-old age group or that of $\geq 50$-year-old age group(FigureS1 A). Moreover, the proportion of moderate to severe stress in $\leq 30$-year-old group and 30 to 40 -year-old group was significantly higher than that in 40 to 50 year-old age group (FigureS1 B). No significant difference was observed on the median PSS among 
HCWs working in different levels of hospitals in fighting against the COVID-19 outbreak; however, the hospital level was weakly correlated with the stress level. Nevertheless, significant differences were observed in PSS of HCWs with different professional titles, among them nurses had the highest median score (14, IQR: 10-18).The median PSS of the physicians was significantly lower than that of the nurses; however, the proportion of reports of severe stress was significantly higher than that of nurses $(4.1 \% \mathrm{vs}$. $1.7 \%, P=0.018$ )(FigureS1 $C$ and $D$ ). Work experience was negatively correlated with the perceived stress degree, and experienced workers had lower median perceived stress score and reported lower proportion of moderate or severe stress.

\section{Demographic variables and general anxiety}

For general anxiety, Table3 showed that the median GAD-7 score of female HCWs was significantly higher than that of male HCWs. Age was significantly associated with general anxiety degree, and HCWs younger than 30 years old had the lowest median anxiety score and the lowest proportion of reports of moderate to severe anxiety (table3) and (FigureS2 A and B). Well-educated respondents had a significantly higher median anxiety score( 3.5 vs. $2, P<0.001)$. A statistical difference was observed in the median anxiety score among HCWs working in different levels of hospitals and different departments during the fight against the COVID-19 outbreak (table3). Pairwise comparison showed that HCWs working in the emergency department had the highest GAD score (FigureS2 C).

\section{Demographic variables and depression}

As shown in Table4, the depression score showed a statistical difference between female and male HCWs, among different educated groups, and among different age groups $(P<0.05)$. Further pairwise comparison among different age groups found that 30 to 40 -year-old group had the highest PHQ9 score(Figure S3).

\section{Discussion}

The COVID-19 outbreak was unique in its extremely fast transmission rate. It has brought heavy stress to frontline HCWs, especially in the early stage. In China, during the COVID-19 outbreak, many HCWs and medical protective equipment were dispatched to Wuhan City and Hubei Province to rapidly control the epidemic and address the medical shortage in the central epidemic area. A prevention strategy may increase the psychological pressure on medical staff in noncentral epidemic areas. Therefore, although different psychological effects of COVID-19 on the general public and healthcare providers have been reported [10-12], the present work focuses on the psychological status of frontline HCWs working outside the central epidemic area during the initial stage of the fight against COVID-19 in China. The results showed that more than half of the frontline HCWs working outside central epidemic area faced moderate to severe perceived stress, and approximately $23 \%$ of them could even be diagnosed with moderate to severe anxiety or major depression. In addition, we found that some demographic data (e.g., female gender) were associated with a high perceived stress. To the best of our knowledge, this study is the first 
to assess the psychological effect of the COVID-19 outbreak on frontline HCWs fighting against COVID-19 outside the central epidemic area.

Data from the present study showed that female HCWs suffered a greater psychological effect of the COVID-19 outbreak and higher levels of stress, general anxiety, and depression compared with male HCWs. This finding corresponds to previous studies of immediate psychological response of general population on the COVID-19 outbreak during early stage in China [12] and extensive epidemiological studies that found that women are at high risk of depression [19]. Age was another social factor beyond gender that was clearly related to the mental stress of the frontline HCWs during the early stage of the fight against COVID-19 in China. Age was negatively associated with perceived stress levels, but positively correlated with anxiety levels. The reason for this finding can be attributed to young medical workers, especially the post-90s generation, mostly having little work experience and are facing public health events,such as the COVID-19, for the first time in their career.Therefore, health authorities should conduct psychological counseling for these high-risk groups early to relieve their perceived pressure, thereby reducing the rate of work errors due to psychological stress.

The analysis results showed that the general anxiety level of HCWs in the emergency department was significantly higher than that of HCWs in isolate wards or fever clinics. This notion may be due to the fact that HCWs working in isolated wards and fever clinicsare voluntarily selected and have sufficient psychological preparation. Moreover, the isolated ward staff comprises of middle-level backbone with rich working experience and strong psychological tolerance. Isolation wards have the best protection facilities and technical guarantee. Furthermore, the isolation ward staff is more knowledgeable about the epidemic than their general emergency colleagues. Therefore, nonisolated wards and outpatient clinic staff must perform outbreak prevention and control skills training and psychological intervention.

Although the work of different professional staff is equally important in fighting the epidemic, the difference in their composition makes them differently stressed during COVID-19 outbreak. The results of this study indicated that compared to physicians, nurses had obviously higher perceived stress. The difference may be due to more opportunities for nurses to be exposed to the secretions and blood of patients with COVID-19, and the unit work time is longer. This result may also be related to the fact that in China, nurses are mainly female and are generally younger than physicians; thus, they have less stress resistance.

This study has several limitations. First,given the limitation of the conditions during the epidemic, we only selected the frontline medical staff in one region for investigation, which may not be able to completely represent the mental state of all frontline medical staff. Second, we could not conduct targeted interventions for these persons nor perform a comparative study of the psychological state of these populations before and after a period due to the ethical requirements on anonymity and confidentiality. Finally, we only evaluated the mental state of frontline staff in noncentral epidemic areas and did not compare with central and other staff. Therefore, a comparative study of the mental status of frontline and nonfrontline workers in different epidemic-resistant areas must be performed in the future to provide 
suggestions for the development of psychological intervention strategies when during public health emergencies.

In summary, the result suggested that during the initial stage of fighting against COVID-19 outside the central epidemic area in China, more than half of the frontline HCWs suffered moderatetosevere perceived stress, and nearly $23 \%$ of them reported moderatetosevere anxiety or depression. Female gender, low hospital level, and emergency department were associated with a high level of perceived stress. Nurses also had a higher perceived stress than that of physician colleagues.

\section{Abbreviations}

COVID-19ðcoronavirus disease;HCWs :Healthcare workers;C-PSS-10:Chinese simple Perceived Stress Scale 10 ;GAD-7:General Anxiety Disorder Scale ;PHQ9:Patient Health Questionnaire-9;

\section{Declarations}

\section{Ethics approval and consent to participate}

This study was approved by the ethics committee of Shanghai changhai Hospital. Participants read and singed informed consent agreements prior to the initiation of the study.

\section{Consent for publication}

Not applicable

\section{Availability of data and material}

The datasets used and/or analysed during the current study are available from the corresponding author on reasonable request.

\section{Competing interests}

The authors declare that they have no competing interests.

\section{Funding}

This study was supported by Grants from Shanghai Natural Science Fund, No.16ZR1400400 and Wu Jieping Medical Foundation Liver Disease Medical Department (LSWJPMF-102-17001).

\section{Authors' contributions}

Liu YY collected data and performed the data analysis;

XinSheng Liu implement questionnaires 
Bai Gao make and implement questionnaires

ChengZhong Li conceived the study and participated in the design of the study;

Liang XS conceived the study and participated in the design of the study; performed the data analysis and drafted the manuscript;

All authors have read and approved the final manuscript.

\section{Acknowledgements:}

Not applicable.

\section{References}

1.China Pouc.Emergencies preparedness, response, Disease outbreak news, World Health Organization (WHO).https://wwwwhoint/csr/don/05-january-2020-pneumonia-of-unkown-cause-china/en/2019.

2.Lai CC, Shih TP, Ko WC, Tang HJ, Hsueh PR. Severe acute respiratory syndrome coronavirus 2 (SARSCoV-2) and coronavirus disease-2019 (COVID-19): The epidemic and the challenges. Int J Antimicrob Agents.2020, 55(3):105924.

3.He F, Deng Y, Li W. Coronavirus Disease 2019 (COVID-19): What we know? J Med Virol.2020.

4.Ran L, Chen X, Wang Y, Wu W, Zhang L, Tan X. Risk Factors of Healthcare Workers with Corona Virus Disease 2019: A Retrospective Cohort Study in a Designated Hospital of Wuhan in China. Clin Infect Dis.2020.

5.web. Ni. 3387 cases of healthcare workers infected with novel coronavirus disease 2019. Available at: https://newsifengcom/c/7uKe45oGSZM2020, [Accessed on 28 February 2020].

6.Maunder R. The experience of the 2003 SARS outbreak as a traumatic stress among frontline healthcare workers in Toronto: lessons learned. Philosophical Transactions of the Royal Society of London Series B: Biological Sciences.2004, 359(1447):1117-1125.

7.Shultz JM, Baingana F, Neria Y. The 2014 Ebola outbreak and mental health: current status and recommended response.JAMA.2015, 313(6):567-568.

8.Lee SH, Juang YY, Su YJ, Lee HL, Lin YH, Chao CC. Facing SARS: psychological impacts on SARS team nurses and psychiatric services in a Taiwan general hospital. Gen Hosp Psychiatry.2005, 27(5):352-358.

9.Lin CY, Peng YC, Wu YH, Chang J, Chan CH, Yang DY. The psychological effect of severe acute respiratory syndrome on emergency department staff. Emerg Med J.2007, 24(1):12-17. 
10.Huang JZ, Han MF, Luo TD, Ren AK, Zhou XP. Mental health survey of 230 medical staff in a tertiary infectious disease hospital for COVID-19. Zhonghua Lao Dong Wei Sheng Zhi Ye Bing Za Zhi.2020, 38(0):E001.

11.Li Z, Ge J, Yang M, Feng J, Qiao M, Jiang R, Bi J, Zhan G,et al. Vicarious traumatization in the general public, members, and non-members of medical teams aiding in COVID-19 control. Brain Behav Immun.2020.

12.Wang C, Pan R, Wan X, Tan Y, Xu L, Ho CS, Ho RC. Immediate Psychological Responses and Associated Factors during the Initial Stage of the 2019 Coronavirus Disease (COVID-19) Epidemic among the General Population in China. Int J Environ Res Public Health.2020, 17(5).

13.Wang Z, Chen J, Boyd JE, Zhang H, Jia X, Qiu J, Xiao Z. Psychometric properties of the Chinese version of the perceived stress scale in policewomen.PLoS One.2011, 6(12):e28610.

14.Spitzer RL, Kroenke K, Williams JB, Löwe B. A brief measure for assessing generalized anxiety disorder - The GAD-7.Arch Int Med.2006, 106(10):1092-1097.

15.Kroenke K, Spitzer RL, Williams JB.The PHQ-9: validity of a brief depression severity measure. J Gen Intern Med.2001, 16(9):606-613.

16.Hinz A, Klein AM, Brahler E, Glaesmer H, Luck T, Riedel-Heller SG, Wirkner K, Hilbert A. Psychometric evaluation of the Generalized Anxiety Disorder Screener GAD-7, based on a large German general population sample. J Affect Disord.2017, 210:338-344.

17.Meng R, Li J, Wang Z, Zhang D, Liu B, Luo Y, Hu Y, Yu C. The Chinese version of the Perceived Stress Questionnaire: development and validation amongst medical students and workers. Health Qual Life Outcomes .2020, 18(1):70.

18.Adewuya $\mathrm{AO}^{1}$, Ola BA, Afolabi 00.Validity of the patient health questionnaire (PHQ-9) as a screening tool for depression amongst Nigerian university students.J Affect Disord.2006, 96(1-2):89-93.

19.Lim GY, Tam WW, Lu Y, Ho CS, Zhang MW, Ho RC.Prevalence of Depression in the Community from 30 Countries between 1994 and 2014. Sci Rep.2018, 8(1):2861.

\section{Tables}

Table1: Demographic characteristics of the participants $(n=1315)$ 


\begin{tabular}{|c|c|}
\hline Characteristics & Percent, n (\%) \\
\hline Age, median (Interquartile, IQR), yr & $37(28-47)$ \\
\hline$\leq 30$ & $426 \square 32.4 \square$ \\
\hline $30 \sim 40$ & 381₫29.0॰ \\
\hline $40 \sim 50$ & $356 \square 27.1 \square$ \\
\hline$\geq 50$ & 152ロ11.6ロ \\
\hline male: female & 316๘999 \\
\hline \multicolumn{2}{|l|}{ Education degree } \\
\hline Bachelor degree & $656 \square 49.9 \square$ \\
\hline Lower than bachelor & $659 \square 50.1 \square$ \\
\hline CDC & $31 \square 2.4 \square$ \\
\hline \multicolumn{2}{|l|}{ Classification } \\
\hline Grade 3 & $168 \square 12.8 \square$ \\
\hline Grade 2 & $215 \square 16.3 \square$ \\
\hline Community & 377ロ28.7ロ \\
\hline $\begin{array}{c}\text { Others } \\
\text { Department }\end{array}$ & $524 \square 39.8 \square$ \\
\hline Fever clinic & $426 \square 32.4 \square$ \\
\hline Emergency & $168 \square 12.8 \square$ \\
\hline Isolation ward & $218 \square 16.6 \square$ \\
\hline Laboratory or Radiology & 503ロ38.3ロ \\
\hline \multicolumn{2}{|l|}{ Professional titles } \\
\hline Nurse & 577ロ43.9ロ \\
\hline Technician & $120 \square 9.1 \square$ \\
\hline Hygiene & $106 \square 8.1 \square$ \\
\hline \multicolumn{2}{|l|}{ Working time } \\
\hline$<10$ years & $598 \square 45.5 \square$ \\
\hline$\geq 10$ years & 717ロ54.5凸 \\
\hline
\end{tabular}

CDC: center for disease control and prevention.

Table2: Demographic characteristic and perceived stress 


\begin{tabular}{|c|c|c|c|c|c|c|}
\hline \multirow[t]{2}{*}{ Characteristics } & \multicolumn{2}{|c|}{$\begin{array}{c}\text { Stress } \\
\end{array}$} & \multicolumn{2}{|c|}{ P Value } & \multicolumn{2}{|c|}{ Spearman§ } \\
\hline & Score median(IQR)* & Score $\geq 14, \mathrm{n} \square \% \square \#$ & * & \# & $\mathrm{r}$ & $P$ value \\
\hline \multicolumn{7}{|l|}{ Gender (n) } \\
\hline Male[316ロ & $12(7-17)$ & $128 \square 40.5 \square$ & $<0.001$ & $<0.001$ & 0.09 & $<0.001$ \\
\hline Female $\square 999 \square$ & $14(9-18)$ & $518 \square 51.9 \square$ & & & & \\
\hline \multicolumn{7}{|c|}{ Age, median (interquartile, IQR), yr } \\
\hline$\leq 30(426)$ & $14 \square 10-18 \square$ & $232 \square 54.5 \square$ & $<0.001$ & 0.001 & -0.09 & 0.001 \\
\hline $\begin{array}{l}30 \sim 40(381) \\
40 \sim 50(356) \\
\geq 50(152)\end{array}$ & $\begin{array}{c}14 \square 9.5-18 \square \\
11 \square 7.25-16 \square \\
13 \square 7-17 \square\end{array}$ & $\begin{array}{c}197 \square 51.7 \square \\
146 \square 41 \square \\
71 \square 46.7 \square\end{array}$ & & & & \\
\hline \multicolumn{7}{|l|}{ Education degree } \\
\hline $\begin{array}{l}\text { Bachelor degree( } 656) \\
\text { Lower than bachelor(659) }\end{array}$ & $\begin{array}{l}13 \square 9-18 \square \\
14 \square 9-17 \square\end{array}$ & $\begin{array}{c}315 \square 48 \square \\
331 \square 50.2 \square\end{array}$ & 0.59 & 0.42 & 0.02 & 0.42 \\
\hline \multicolumn{7}{|l|}{ Hospital classification $\square \mathrm{N}=1284 \square$} \\
\hline Grade 3(168) & 1108-17口 & $69 \square 41.1 \square$ & 0.08 & 0.10 & -0.06 & 0.02 \\
\hline $\begin{array}{l}\text { Grade 2(215) } \\
\text { Community(377) } \\
\text { Others(524) }\end{array}$ & $\begin{array}{l}13 \square 9-18 \square \\
13 \square 9-17 \square \\
14 \square 9-18 \square \\
\end{array}$ & $\begin{array}{c}103 \square 47.9 \square \\
181 \square 48 \square \\
272 \square 51.9 \square \\
\end{array}$ & & & & \\
\hline \multicolumn{7}{|l|}{ Department } \\
\hline $\begin{array}{l}\text { Isolation ward } \square 218 \square \\
\text { Fever clinic } \square 426 \square \\
\text { Emergency } \square 168 \square \\
\text { Laboratory or Radiology(503) }\end{array}$ & $\begin{array}{c}13(8-17.25) \\
13(9-17) \\
15(10-19) \\
14(9-18) \\
\end{array}$ & $\begin{array}{l}101 \square 46.3 \square \\
193 \square 45.3 \square \\
94 \square 56 \square \\
258 \square 51.3 \square \\
\end{array}$ & 0.10 & 0.06 & 0.05 & 0.06 \\
\hline \multicolumn{7}{|l|}{ Professional titles } \\
\hline $\begin{array}{l}\text { Physician } \\
\text { Nurse } \\
\text { Technician } \\
\text { Hygiene } \\
\end{array}$ & $\begin{array}{c}13(8-17) \\
14(10-18) \\
14(9-18) \\
14(8-18) \\
\end{array}$ & $\begin{array}{l}229 \square 44.7 \square \\
297 \square 51.1 \square \\
62 \square 51.7 \square \\
58 \square 54.7 \square \\
\end{array}$ & 0.02 & 0.07 & I & I \\
\hline \multicolumn{7}{|l|}{ Working time } \\
\hline $\begin{array}{l}<10 \text { years, n (\%) } \\
\geq 10 \text { years, n (\%) }\end{array}$ & $\begin{array}{c}14(10-18) \\
12(8-17)\end{array}$ & $\begin{array}{l}330 \square 55.2 \square \\
316 \square 44.1 \square \\
\end{array}$ & $<0.001$ & $<0.001$ & -0.11 & $<0.001$ \\
\hline
\end{tabular}

${ }^{\S}$ Correlation between demographic characteristics and perceived stress degree

Table 3: Demographic characteristic and general anxiety 


\begin{tabular}{|c|c|c|c|c|c|c|}
\hline \multirow[t]{2}{*}{ Characteristics } & \multicolumn{2}{|c|}{ Anxiety } & \multicolumn{2}{|c|}{ P Value } & \multicolumn{2}{|c|}{ Spearman ${ }^{\S}$} \\
\hline & Score median(IQR)* & Score $\geq 10, n[\%$ 口\# & * & $\#$ & $\mathrm{r}$ & P value \\
\hline \multicolumn{7}{|l|}{ Gender (n) } \\
\hline Male[316ロ & $2 \square 0-6 \square$ & $27 \square 8.5 \square$ & 0.02 & 0.15 & 0.04 & 0.15 \\
\hline Female $[999 \square$ & $3 \square 0-7 \square$ & $114 \square 11.4 \square$ & & & & \\
\hline \multicolumn{7}{|c|}{ Age, median (interquartile, IQR), yr } \\
\hline$\leq 30(426)$ & $2 \square 0-6 \square$ & $29 \square 6.8 \square$ & $<0.001$ & 0.01 & 0.08 & 0.003 \\
\hline $\begin{array}{l}30 \sim 40(381) \\
\quad 40 \sim 50(356) \\
\geq 50(152)\end{array}$ & $\begin{array}{l}4 \square 0-7 \square \\
3 \square 0-7 \square \\
4 \square 0-7 \square\end{array}$ & $\begin{array}{l}47 \square 12.3 \square \\
42 \square 11.8 \square \\
23 \square 15.1 \square\end{array}$ & & & & \\
\hline \multicolumn{7}{|l|}{ Education degree } \\
\hline $\begin{array}{l}\text { Bachelor degree( 656) } \\
\text { Lower than bachelor(659) }\end{array}$ & $\begin{array}{l}3.5 \square 0-7 \square \\
2 \square 0-6 \square\end{array}$ & $\begin{array}{l}\text { 77011.7ロ } \\
64 \square 9.7 \square\end{array}$ & $<0.001$ & 0.24 & -0.03 & 0.24 \\
\hline \multicolumn{7}{|l|}{ Hospital classification $\square \mathrm{N}=1284 \square$} \\
\hline Grade 3(168) & $3 \square 0-6 \square$ & $14 \square 8.3 \square$ & 0.05 & 0.71 & -0.03 & 0.28 \\
\hline $\begin{array}{l}\text { Grade } 2(215) \\
\text { Community(377) } \\
\text { Others }(524)\end{array}$ & $\begin{array}{l}3 \square 0-7 \square \\
2 \square 0-6 \square \\
3 \square 0-7 \square\end{array}$ & $\begin{array}{l}22 \square 10.2 \square \\
39 \square 10.3 \square \\
60 \square 11.5 \square\end{array}$ & & & & \\
\hline \multicolumn{7}{|l|}{ Department } \\
\hline $\begin{array}{l}\text { Isolation ward } \square 218 \square \\
\text { Fever clinic } \square 426 \square \\
\text { Emergency } \square 168 \square \\
\text { Laboratory or Radiology(503) }\end{array}$ & $\begin{array}{l}2(0-7) \\
3(0-7) \\
4(1-7) \\
3(0-7)\end{array}$ & $\begin{array}{c}22 \square 10.1 \square \\
52 \square 12.2 \square \\
19 \square 11.3 \square \\
48 \square 9.5 \square\end{array}$ & 0.03 & 0.60 & -0.02 & 0.46 \\
\hline \multicolumn{7}{|l|}{ Professional titles } \\
\hline $\begin{array}{l}\text { Physician } \\
\text { Nurse } \\
\text { Technician } \\
\text { Hygiene } \\
\end{array}$ & $\begin{array}{l}3(0-7) \\
3(0-7) \\
2(0-6) \\
3(0-7) \\
\end{array}$ & $\begin{array}{l}57 \square 11.1 \square \\
65 \square 11.3 \square \\
7 \square 5.8 \square \\
12 \square 11.3 \square \\
\end{array}$ & 0.57 & 0.35 & I & I \\
\hline \multicolumn{7}{|l|}{ Working time } \\
\hline $\begin{array}{l}<1 \text { 0years, } \mathrm{n}(\%) \\
\geq 10 \text { years, } \mathrm{n}(\%)\end{array}$ & $\begin{array}{l}3(0-7) \\
3(0-7)\end{array}$ & $\begin{array}{c}51 \square 8.5 \square \\
90 \square 12.6 \square\end{array}$ & 0.09 & 0.02 & -0.07 & 0.02 \\
\hline
\end{tabular}

$\S_{\text {Correlation between demographic characteristics and general anxiety degree }}$

Table 4: Demographic characteristic and depression 


\begin{tabular}{|c|c|c|c|c|c|c|}
\hline \multirow[t]{2}{*}{ Characteristics } & \multicolumn{2}{|c|}{ Depression } & \multicolumn{2}{|c|}{ P Value } & \multicolumn{2}{|c|}{ Spearman $^{\S}$} \\
\hline & Score median(IQR) ${ }^{*}$ & Score $\geq 10, \mathrm{n} \square \% \square^{\#}$ & * & \# & $\mathrm{r}$ & $P$ value \\
\hline \multicolumn{7}{|l|}{ Gender (n) } \\
\hline Male[316! & $2 \square 0-6 \square$ & 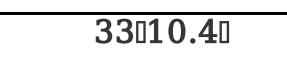 & 0.005 & 0.21 & 0.03 & 0.21 \\
\hline Female[999] & $4 \square 1-8 \square$ & 131013.10 & & & & \\
\hline \multicolumn{7}{|c|}{ Age, median (interquartile,IQR), yr } \\
\hline$\leq 30(426)$ & 300-70 & $46 \square 10.8 \square$ & 0.04 & 0.56 & 0.025 & 0.36 \\
\hline $\begin{array}{l}30 \sim 40(381) \\
\quad 40 \sim 50(356) \\
\geq 50(152)\end{array}$ & $\begin{array}{l}4 \square 1-8 \square \\
3 \square 1-7 \square \\
3 \square 0-7 \square\end{array}$ & $\begin{array}{l}53 \square 13.9 \square \\
44 \square 12.4 \square \\
21013.8 \square\end{array}$ & & & & \\
\hline \multicolumn{7}{|l|}{ Education degree } \\
\hline $\begin{array}{l}\text { Bachelor degree( } 656) \\
\text { Lower than bachelor(659) }\end{array}$ & $\begin{array}{l}4 \square 1-8 \square \\
3 \square 0-7 \square\end{array}$ & $\begin{array}{l}96 \square 14.6 \square \\
68 \square 10.3 \square\end{array}$ & $<0.001$ & 0.02 & -0.06 & 0.02 \\
\hline \multicolumn{7}{|c|}{ Hospital classification $\square \mathrm{N}=1284 \square$} \\
\hline Grade 3(168) & $3 \square 0-7 \square$ & $25 \square 14.9 \square$ & 0.23 & 0.42 & -0.005 & 0.86 \\
\hline $\begin{array}{l}\text { Grade } 2(215) \\
\text { Community }(377) \\
\text { Others }(524)\end{array}$ & $\begin{array}{l}4 \square 1-8 \square \\
3 \square 0-7 \square \\
3 \square 1-8 \square\end{array}$ & $\begin{array}{l}25 \square 11.6 \square \\
38 \square 10.1 \square \\
66 \square 12.6 \square\end{array}$ & & & & \\
\hline \multicolumn{7}{|l|}{ Department } \\
\hline $\begin{array}{l}\text { Isolation ward } \square 218 \square \\
\text { Fever clinic } 426 \square \\
\text { Emergency } \square 168 \square \\
\text { Laboratory or Radiology(503) }\end{array}$ & $\begin{array}{l}3(0-7) \\
3(0-7) \\
4(1-8) \\
3(1-7)\end{array}$ & $\begin{array}{l}25 \square 11.5 \square \\
52 \square 12.2 \square \\
31 \square 18.5 \square \\
56 \square 11.1 \square\end{array}$ & 0.18 & 0.09 & -0.004 & 0.89 \\
\hline \multicolumn{7}{|l|}{ Professional titles } \\
\hline $\begin{array}{l}\text { Physician } \\
\text { Nurse } \\
\text { Technician } \\
\text { Hygiene } \\
\end{array}$ & $\begin{array}{c}3(1-7) \\
3(0-8) \\
4(0.25-7) \\
3(0.75-7) \\
\end{array}$ & $\begin{array}{l}63 \square 12.3 \square \\
73 \square 12.7 \square \\
14 \square 11.7 \square \\
14 \square 13.2 \square \\
\end{array}$ & 0.91 & 0.99 & I & I \\
\hline \multicolumn{7}{|l|}{ Working time } \\
\hline $\begin{array}{l}<10 \text { years, n (\%) } \\
\geq 10 \text { years, n (\%) }\end{array}$ & $\begin{array}{l}4(0-8) \\
3(1-7)\end{array}$ & $\begin{array}{l}77 \square 12.9 \square \\
87 \square 12.1 \square\end{array}$ & 0.43 & 0.69 & -0.01 & 0.69 \\
\hline
\end{tabular}

${ }^{\S}$ Correlation between demographic characteristics and depression degree

\section{Supplementary Files}

This is a list of supplementary files associated with this preprint. Click to download.

- Supplementfile.docx

- Supplementfile.docx

- Supplementfile.docx

- FigureS3.jpg

- FigureS3.jpg

- FigureS3.jpg

- FigureS2.jpg

- FigureS2.jpg

- Figures2.jpg

- FigureS1.jpg 
- FigureS1.jpg

- FigureS1.jpg

Page 15/15 